\title{
Review on Seismic Analysis of INTZE Water Tank with Different Staging Configuration
}

\author{
Vishal D Pawde ${ }^{1}$ \\ UG Student Civil Engineering Department, \\ G H Raisoni University, Madhya Pradesh, \\ India.
}

\author{
Shahayajali Sayyed ${ }^{2}$ \\ Asst. Professor, Civil Engineering Department \\ G H Raisoni University, Madhya Pradesh, \\ India.
}

\begin{abstract}
Reinforcement concrete elevated tanks are very important and useful structures . An elevated tank behaves like an inverted pendulum which consists of huge amount of water at top staging .As known from very upsetting experience in many places of world collapse of tank and due to this heavy damages during earthquakes due to this reason many studies done for dynamic behavior of water containers, most of them are concern with cylindrical tanks.. The economic lifetime of this Rec tanks are usually in the range of 40-70 years. Staging is responsible for lateral resistance of complete structure. The objectives of this is study to understand the behavior of different staging system, under different tank conditions.

Response analysis staging configuration is carried out on different types of bracing system of elevated water tank in all zone by using STAAD Pro V8i.
\end{abstract}

Keywords: Water tank, staging system staad pro, earthquake.

\section{INTRODUCTION:}

Water is lifeline for every kind of creature in this world. In all over the world water tank are used immense by municipal, residential and industrial for water supply. Indian sub-continent is highly unshielded to natural disaster like earthquake, flood etc. Earthquake occupy first place in vulnerability. Hence it is necessary to learn to live with this event. This RCC Structures have a configuration that is especially unprotected to horizontal forces like (earthquake) due to large total mass concentrated at top of staging supporting structure.

However a general purpose structural analysis program generally exist in every engineering office. So the evaluation of the bearing of these structural analysis program in the design of elevated tanks is important from an engineering point of view and it will be help to attending the application and result to designers. There is a second important reason that should be considered .That is simplified models are used for straightforward estimate of the seismic hazard of exiting elevated tanks. Only if the estimated risk is high, it is convenient to measure all the data that are required by the general finite element coded and to spent time and many to prepare reliable general model.

\section{OBJECTIVES:}

- To determine the base shear force on water tank.

- Comparison of base shear for different staging system.

\section{LITERATURE REVIEW:}

This section present a review on various literatures to highlight development and application of different techniques on elevated water tank structures. The main purpose to exhaustive literature surveys areas following. Firstly, it was meant for obtaining a complete picture of various soil condition and seismic zone for the design of elevated water tanks .Secondly, the staging patterns of column and shaft type staging for supporting system of water tanks and the effect of soil structures interaction on the structure and thirdly, the optimizing construction of silo structure achieving he maximum structural stability at the same time . Literature review related to present work shows the research proceeds along following directions.

S.C.DUTTA(2000): studied an assessed the seismic torsion vulnerability of elevated tanks with RC frame type staging objective of the paper is to estimate the range of variation of natural period ratio for casually constructed reinforced concrete elevated water tanks with frame type staging for computing out their vulnerability. The study represents that there is only limited scope for changing natural period ratio by modifying the number of columns $\mathrm{Nc}$, number of panels $\mathrm{Np}$, and the relative column and beam stiffness parameter.

SUDHIR JAIN and SAJJAD SAMEER U(1994): studied about the necessary requirement in Indian codes for seismic design of elevated water tank and studied the primary objective is to review with the IS code codes of other country and study report based on the investigations made . By the comparative study they have proposed the recommendations for the IS code with comparative study of codes of other countries.

TOKHI AJMAL (2019): has studied the seismic analysis and comparison of intze water tank, circular water tank and rectangular water tank and having RCC frame staging in zone III and V during empty, half and fully filled condition by response spectrum method using STTAD Pro V8i . In this paper author illustrated that the base shear of the intze tank is greater than a rectangular tank and circular tank in zone III during all three condition (i.e. empty, full and half ) whereas in zone $\mathrm{V}$ base shear of rectangular water tank is more as compared to intze and circular water tank. He mention the statement that the maximum design base shear is governing factor to be consider for design of elevated water which can be obtain during full filled condition. In zone III circular water tank have maximum 
displacement during a full filled condition whereas in in Zone $\mathrm{V}$ intze tank have a maximum displacement during fill condition The time period is more for intze circular water tank in full filled condition in comparison to rectangular tank and is independent of zones, Author neglected base moment during his research.

Dr. SUCHITA HIRDE \& Dr.MANOJ HEDAOO(2011): studied the seismic performance of elevated tanks for various seismic zone of India for various heights and capacity of tanks for different soil conditions. The effect of height of water tank, earthquake zones and soil condition on earthquake forces have been presented in this paper with the help of analysis of 240 models of various parameter, study concluded that seismic forces are directly proportional to seismic zone, capacity of tank, and inversely proportional to height of supporting system.
SHEKHAR
CHANDRA
\&
RANA

ROY:(2009), investigated about the dynamic behavior of RCC elevated tank with soil structure interaction primary objective of this paper is to check the effect of soil structure interaction on the component in empty condition and to identify the torsion vulnerability of shaft supported water tank. The investigation evaluates impulsive lateral period and impulsive torsion to lateral period ratio of system incorporating the effect of soil structure interaction and validating the results against finite element analysis.

SOHEIL SOROUNSHIA(2011): investigated about the seismic performance of RCC elevated water tanks with staging and exhibition damage pattern. In this study the aim is to obtain the damage pattern in reservoir by using analytic method, with the help of finite element analysis ,method .In comparison with reinforced concrete elevated water tanks with shaft staging the water tank with frame staging have shown better seismic behavior to resistant against lateral loads.

\section{CONCLUSION:}

- Base shear of full water tank and empty tank are increased with seismic zone II-V because of zone factor, responsible reduction factor etc. while considering seismic analysis.

- Present study is attempt to focus on various aspect of study for dynamic analysis of elevated water tank which are still not taken as mater of interest.

- Based on literature review it is observed that the analytic study was carried out and the results determine that the elevated water tanks are more vulnerable to seismic activities due to earthquake.

- In some research the variation in geometry is not consider as circular shape and rectangular shape behave completely different in stress distribution manner.

- Three cases are considered :
a. Empty tank
b. Fully filled tank
c. partially filled tank

\section{REFERENCES:}

[1] S.C . Dutta and C.V.R Murthy, (2000), "Sassing the seismic torsion vulnerability of elevated tanks with RCC frame type staging", soil dynamic and earthquake engineering, volume 19, issue 3, April 2000.

[2] Sudhir K.Jain, Sajjad Sameer U(1994): "A review of requirement in Indian codes for a seismic design of a elevated water tanks", Journal of structural engineering, volume20,Pp119-128.

[3] Tokhi Ajmal \& Sahil Arora, "Seismic analysis of elevated water tank, circular water tank and rectangular and response spectrum analysis", International Journal of civil engineering and Technology, vol.10, issue:03march 2019, pp 2519-2527.

[4] Dr. Suchita Hirde, Dr Manoj Hedaoo,(2011), "Seismic performance of elevated water tanks", International Journal Of Advance Engineering Research And Studies.

[5] Sekhar Chandra Dutta,Rana roy, (2009), "Dynamic Behavior Of Elevated Water Tank With Soil Structure Interaction". Elsevier/Engineering Structures 31(2009) 2617-2629.

[6] Soheil Souroushnia, Sh. Tavousi Tafreshi.F.Omidinassab,N,Beheshtian sajad soroushnia(2011): "Seismic Performances Of RC Elevated Water Tanks With Frame Staging and Exhibition Damage Pattern", The Twelfth East AsiaPacific Conference On A Structural Engineering and Construction.

[7] Shahayajali Sayyed "Comparative Analysis of Beam-Column Join of Elevated Water Tank" IJSART - Volume 3 Issue 10 - october 2017. 